\title{
Multidetector CT Angiography for Pre-Operative Evaluation of Living Renal Donors - An Observational Study at IGIMS, Patna
}

\author{
Manisha Kumari ${ }^{1}$, Sanjay Kumar Suman², Govind Kumar², Manmit Patel ${ }^{4}$ \\ 1, 2, 4 Department of Radiodiagnosis, Indira Gandhi Institute of Medical Sciences, IGIMS, Patna, India. \\ ${ }^{3}$ Department of General Medicine, Indira Gandhi Institute of Medical Sciences, IGIMS, Patna, India.
}

\section{ABSTRACT}

\section{BACKGROUND}

We wanted to assess the renal abnormalities including parenchymal, arterial, venous and collecting systems that preclude renal donation or altered surgical approach on the basis of CT angiography.

\section{METHODS}

This is a hospital based retrospective observational study. 55 donors (110 kidneys) had undergone preoperative CT renal angiography. The data were collected from last 3 years (December 2016 - December 2019) and analyzed. Two different radiologists interpreted the results unaware of the findings of each other. Final report depended upon the common consensus of both the radiologists.

\section{RESULTS}

The percentage of multiple renal arteries, early branching of renal artery and retrocaval right renal artery were $30 \%, 5.45 \%$ and $3.64 \%$ respectively. The percentage of multiple renal veins, circumaortic renal vein and retroaortic renal veins were $7.27 \%, 5.45 \%$ and $1.82 \%$ respectively. The late confluence of renal vein (left side) was found in 1 donor. Renal parenchymal abnormalities were detected in the form of simple cortical cysts and renal calculus. No variation or abnormality was detected in the collecting system.

\section{CONCLUSIONS}

Multi detector computed tomography (MDCT) angiography provides an accurate and reliable tool to evaluate the renal parenchyma, collecting system, vascular anatomy and their variations in the living renal donor. It guides the surgeon immensely in decision making regarding proper donor selection and as to which kidney should be harvested.

\section{KEY WORDS}

MDCT Angiography, Renal Vessels, Anatomic Variations, Living Renal Donor
Corresponding Author: Dr. Govind Kumar, B - 502 Manju Vatika, Gola Road, Bailey Road, Danapur, Patna, Bihar - 801503, India.

E-mail:dr.gks4@gmail.com

DOI: $10.14260 / j e m d s / 2021 / 383$

How to Cite This Article:

Kumari M, Suman SK, Kumar G, et al. Multidetector CT angiography for preoperative evaluation of living renal donors - an observational study at IGIMS, Patna. J Evolution Med Dent Sci 2021;10(25):18521856, DOI: 10.14260/jemds/2021/383

Submission 17-02-2021, Peer Review 23-04-2021, Acceptance 30-04-2021, Published 21-06-2021.

Copyright (C) 2021 Manisha Kumari et al. This is an open access article distributed under Creative Commons Attribution License [Attribution 4.0 International (CC BY 4.0)] 


\section{BACKGROUND}

Renal transplantation leads to a better survival and quality of life in end-stage renal disease patients than dialysis. Laparoscopic nephrectomy from the living renal donor is the gold standard technique of choice for harvesting the kidney. ${ }^{1}$ Laparoscopically medial and posterior aspects of the kidneys are not adequately assessed due to limited surgical exposure and some technical difficulties that may lead to catastrophes. Hence detailed preoperative evaluation of the potential donor is very crucial for the proper donor selection, which kidney to be harvested, best surgical approach for renal harvesting and to minimize post-operative complications for both the donor as well as the recipient. ${ }^{2}$

There are various radiological methods (including traditional renal angiography and excretory urography) for the renal assessment, in which CT Angiography is considered as the best imaging modality for the preoperative evaluation of the living renal donor. ${ }^{3}$ MDCT along with 3D-CT angiography provides accurate anatomic information regarding the renal parenchyma, artery, vein and collecting system. MDCT offers shorter image acquisition times, reduction in tube heating and improved spatial resolution.

We present our experience at this institution using MDCT angiography in renal donors. In this study, we focused on the renal anatomy, it's parenchymal lesion, renal artery, vein and the collecting system, which was very crucial for the radiologist to get familiar with. This could change the plan of action of the renal transplant surgeon.

\section{METHODS}

This is a hospital based retrospective observational study which was conducted for a period of 3 years from December 2016 to December 2019. Fifty-five donors i.e. one hundred ten kidneys had undergone MDCT and 3-D CT angiography for the detailed evaluation of the kidneys. The angiography protocol that we followed in our institute, was the standard of care over the past 5 years and the reporting format for the renal angiography was considered appropriate (predesigned performa).

\begin{tabular}{|cc|}
\hline Scanner & Toshiba Acquallion \\
Tube voltage & $120 \mathrm{KVp}$ \\
Effective current & $150 \mathrm{mAs}$ \\
Rotation time & $0.5 \mathrm{sec}$ \\
Slice thickness & $1.25 \mathrm{~mm}$ \\
Detector collimation & $64 \times 0.5 \mathrm{~mm}$ \\
Intravenous contrast & $120 \mathrm{ml}$ followed by $40 \mathrm{ml}$ saline @ $4 \mathrm{ml} / \mathrm{sec}$ \\
Acquisition phases & NCCT, Arterial (bolus tracking), Venous $(70 \mathrm{sec})$ and \\
Imaging analysis (PACS) & delayed (5 - 10 min) \\
Reconstruction technique & MPR, MIP, 3D-VRT \\
Radiation dose & $20-30 \mathrm{mSv})$ \\
\hline Table 1. Scan Parameters for Data Acquisition and Post \\
Processing in MDCT and 3-D CT Angiography Study \\
Using 128 - Slice MDCT Scan at IGIMS, Patna \\
\hline
\end{tabular}

All the data were reconstructed using the body soft-tissue algorithm. The post-processing / reformatting techniques like MPR (multiplanar reformation) to obtain axial, sagittal and coronal images, MIP (maximum intensity projection) in which brightest densities are projected into the 3D image and 3D-CT Angiography volume rendered technique (VRT) was used as a supplementary image specially for the small vessels. Renal artery and venous anatomy as well as it's variations were evaluated in the arterial (25 sec. post-contrast) and venous phase (55 sec. post-contrast) respectively. Evaluation of the renal collecting systems and ureter was done in the delayed / urographic phases (5 - 10 min post-contrast).

\section{Image Interpretation}

The images were stored in the PACS (picture archiving and communicating system) and were reported by two different radiologists separately in a predesigned performa, unaware of the findings of each other. Then the findings of both the radiologists were analyzed. The information was collected regarding the number of the renal arteries, early branching of arteries and number of veins and their course. If a kidney had two or more renal arteries, then the vessel with greatest diameter was considered as dominant / main artery and others as accessory artery. If the arteries were of same size then it was termed as upper renal artery and lower renal artery. Accessory artery was classified as hilar, polar and capsular depending upon it's course from the aortic origin into the renal parenchyma. Distance between the two arteries was also noted, as this will guide the surgeon to create anastomosis with the recipient iliac artery. If any branch diverged / originated from the renal artery by $1 \mathrm{~cm}^{4}$ or less from the aortic origin, then it was considered as early branching (followed at our institute). Some studies defined early branching if the first branch was either $1.5 \mathrm{~cm}$ or $2 \mathrm{~cm}^{5}$ from the renal ostia. Presence of the soft or calcified plaque or any stenosis in the renal artery and renal venous anomaly like retroaortic and circumaortic were also recorded.

\section{Renal Angiographic Features and It's Implications on Decision for Renal Donation}

As donor safety is of main importance in living donor transplant program, the donor should retain one normal (morphological as well as functional) kidney. If subtle abnormality is detected in one kidney and another is absolutely normal, then the kidney with altered morphology should be used as a transplant kidney. Presence of small renal calculi $(<4 \mathrm{~mm})$ without calyectasis, small cortical cyst $(<5$ $\mathrm{mm})$ or small $(<5 \mathrm{~mm})$ angiomyolipoma is not the contraindication of renal donation. Presence of multiple calculi or calculus of size $>5 \mathrm{~mm}$ requires removal of the stone and it's metabolic analysis. Large Cortical cyst or angiomyolipoma (> $5 \mathrm{~mm}$ ) requires excision of the lesion before transplantation. 2,6

If both the kidneys are normal in morphology, then kidney with less complicated vascular anatomy is chosen. The surgeon often prefers left kidney because of longer vascular pedicle and easy technique. Presence of the accessory artery or polar artery often increases the surgery duration in donor as well as in recipient with increased post-operative complications like arterial thrombosis and later on stenosis. According to rough estimate, small-caliber polar artery of diameter less than $2 \mathrm{~mm}$ may be sacrificed as it will produce graft infarct in less than $10 \%$ of renal volume. ${ }^{7}$

Precise evaluation of the renal arteries is very important aspect for the imaging work-up. It's origin from the aorta, renal artery length till it's first branch, luminal caliber, presence of 
calcified or soft plaque and any other pathology like fibromuscular dysplasia should be carefully looked for, since on the right side, there is inferior vena cava (IVC) and renal artery is retrocaval in location. Hence, it is important to see the relation of first renal artery branch with respect to the IVC. This will immensely help in planning the surgery.

Renal veins and their variations are also important to recognize. There could be one or more than one renal vein on either side. Duplication of right renal vein has been reported in $15 \%$ of renal donors. ${ }^{8}$ Right renal vein is often short and slight oblique course and then drains into IVC. It often doesn't show significant variation. Left renal vein is longer and commonly pre-aortic horizontal course. Sometimes it is having retro-aortic course in which case it follows oblique route. Another uncommon variation is circumaortic left renal vein in which case renal vein is having both pre-aortic and retroaortic course and drains into the IVC either separately or before draining they join to form single renal vein. Site of first venous confluence (IVC side) is identified and length of renal vein from the drainage site to the first venous confluence is measured that will form the renal venous pedicle length on each side which should be minimum $10 \mathrm{~mm}$ in length. In case of venous duplication, pattern of the venous separation e.g. circumferential or craniocaudal, their length and luminal caliber are measured and communicated to the concerned surgeon.

\section{Statistical Analysis}

chi-square test applied using SPSS software to analyze data. Accordingly mean and percentages were estimated.

\section{RESULTS}

MDCT angiographic evaluation was done in 55 patients i.e. 110 kidneys and their vessels were evaluated. Females were the most common candidates for the donor. They constituted 43 out of 55 candidates i.e. $78.18 \%$ of the available donor. Age range was from 24 years to 65 years. Mean age was $45.2(+/-$ 10.5). Most common age group which volunteered for the renal donation was 41 - 50 years of age (18 / 55 i.e. $32.73 \%$ ) followed by 51 - 60 years of age (15 / 55 i.e. $27.27 \%$ ). In the age group of 21 - 40 years all donors were females. Males were the commonest donors in the age group 61 - 70 years i.e. 3 males among 4 donors ( $75 \%$ male). There was one small right kidney (7.4 cm length) and relatively enlarged left kidney (12.8 cm length) in two different donors.

Focal parenchymal lesion in the form of simple cortical cysts was noted. Single cortical cyst was found in 3 different right kidneys and multiple ( $>2$ in number) cortical cysts in 2 different right kidneys and 1 left kidney. Calculi were seen in 1 right and 1 left kidney as tiny concretions without caliectasis which was definitely, not the contraindication of renal harvesting. Extrarenal pathology was detected (that didn't alter the decision of transplant surgeon) in two candidates; one donor was having healed hepatic hydatid cyst and the other one was having uterine multiple fibroids. Three renal arteries were detected in 4 out of 110 kidneys (3.64 \%) and two renal arteries were detected in 29 out of 110 kidneys $(26.36 \%)$ (Figure 1 A \& B). Early branching was noted in 6 kidneys (3 right and 3 left kidneys) among 110 kidneys (5.45 \%) (Figure 1 C \& D). Retrocaval branching was noted in one donor.

\begin{tabular}{|cccc|}
\hline Renal Artery & $\begin{array}{c}\text { Right renal Artery Left Renal Artery (N } \\
\text { (N / \%) }\end{array}$ & / \%) & Total (N / \%) \\
Single & $39 / 35.45$ & $38 / 34.55$ & $77 / 70$ \\
Double & $13 / 11.81$ & $16 / 14.55$ & $29 / 26.36$ \\
Triple or more & $03 / 2.73$ & $01 / 0.91$ & $04 / 3.64$ \\
Total & \multicolumn{3}{|c}{} \\
\hline \multicolumn{4}{c}{ Table 2. Renal Artery Variations } \\
\hline
\end{tabular}

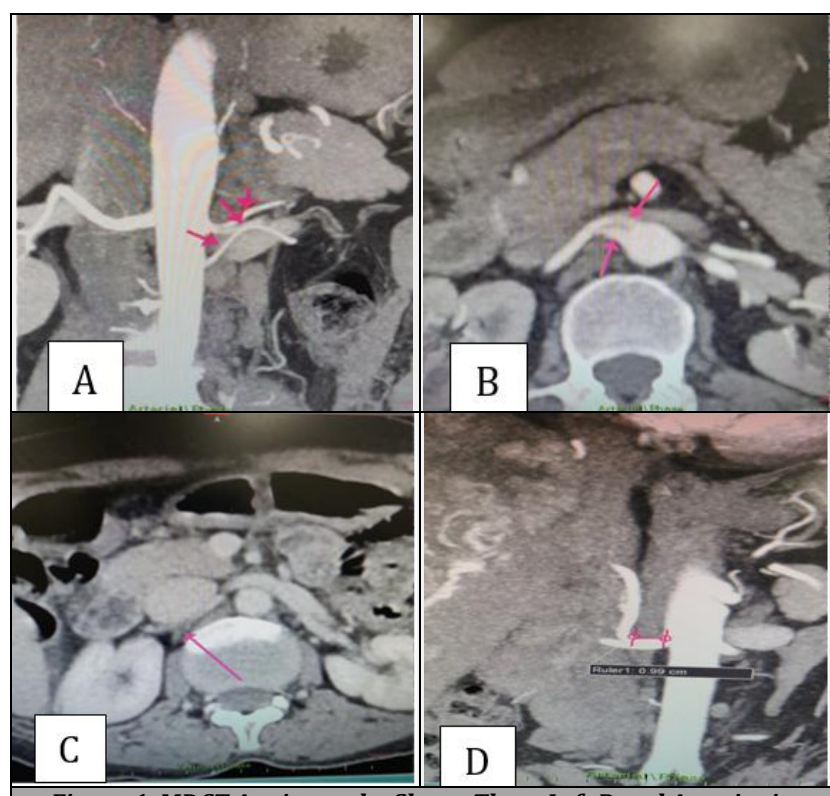

Figure 1. MDCT Angiography Shows Three Left Renal Arteries in Image A (Coronal VRT) with Craniocaudal Separation and Two Right Renal Arteries in Image B (Axial MIP) with Circumferential Separation Very Close to Each Other. Early Branching is Visualized as Retrocaval Branching in Image C (Axial MIP) and at the Medial Border of Inferior Vena Cava (9 mm from the Aortic Origin of Renal Artery) in Image D (Coronal VRT) in Different Donors.

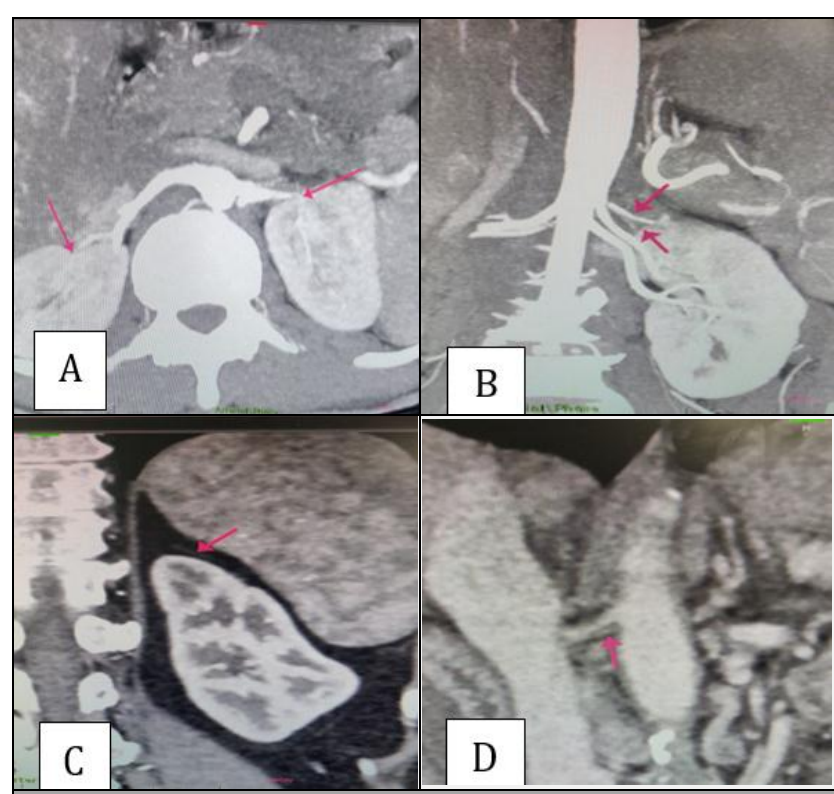

Figure 2. MDCT Angiography. Image A (Thick-Slab Axial VRT) Shows Polar Artery (Arrow Mark) of Both Kidneys at Upper Pole. Right Polar Artery Arises from the Right Renal Artery and Left Polar Artery Arises Directly from the Aorta. Image B (Thick-Slab Coronal VRT) Shows Three Polar Arteries (Middle One is Attenuated - Lower Arrow Mark) Arises from the Aorta and One Main Renal Artery (MRA) in the Left Kidney and One MRA and One Accessory Renal Artery on the Right Side. Image C (coronal MIP) Shows a Thin and Attenuated Left Capsular Artery (Arrow Mark) Arising from the Main Renal Artery and Image D (Coronal MIP) Shows a Hypodense Soft Plaque (Arrow Mark) at the Renal Artery Origin Having a Thickness of $2.7 \mathrm{~mm}$.

In two donors, MRA and accessory renal artery were having same caliber. A total of 6 polar arteries were found among 110 kidneys (5.45\%). Four right-sided kidneys were 
having polar arteries. Three of them arose from the MRA (3 $5.6 \mathrm{~mm}$ away from the aortic origin of MRA) and one directly from the aorta. One polar artery was detected in two left kidneys originating from the abdominal aorta. Both polar arteries that arose from the aorta were cranial to the origin (superior polar artery) of the MRA in our study (Figure $2 \mathrm{~A}$ \& B). Three capsular arteries ( 2 on right side of 2 different donor and 1 on the left side) were detected among 110 kidneys (2.72 $\%$ ), all arising from the renal artery (Figure $2 \mathrm{C}$ ). One donor was having soft plaque in the right renal artery near the ostium; however no significant stenosis was noted (Figure 2 D). The separation between the MRA and accessory artery ranged from $2.5-13 \mathrm{~mm}$ on right side and $2-15 \mathrm{~mm}$ on left side either cranio-caudally or circumferentially.

\begin{tabular}{|c|c|c|c|}
\hline Renal Vein & $\begin{array}{c}\text { Right Renal Vein } \\
\text { (N / \%) }\end{array}$ & $\begin{array}{c}\text { Left Renal Vein } \\
(\mathrm{N} / \%)\end{array}$ & $\begin{array}{c}\text { Total } \\
\text { (N / \%) }\end{array}$ \\
\hline Single & $51 / 46.36$ & $51 / 46.36$ & $102 / 92.72$ \\
\hline Double & $4 / 3.64$ & $4 / 3.64$ & $8 / 7.28$ \\
\hline Triple or more & $0 / 0$ & $0 / 0$ & $0 / 0$ \\
\hline Total & & & 110 \\
\hline \multicolumn{4}{|c|}{ Table 3. Renal Vein Variations } \\
\hline
\end{tabular}

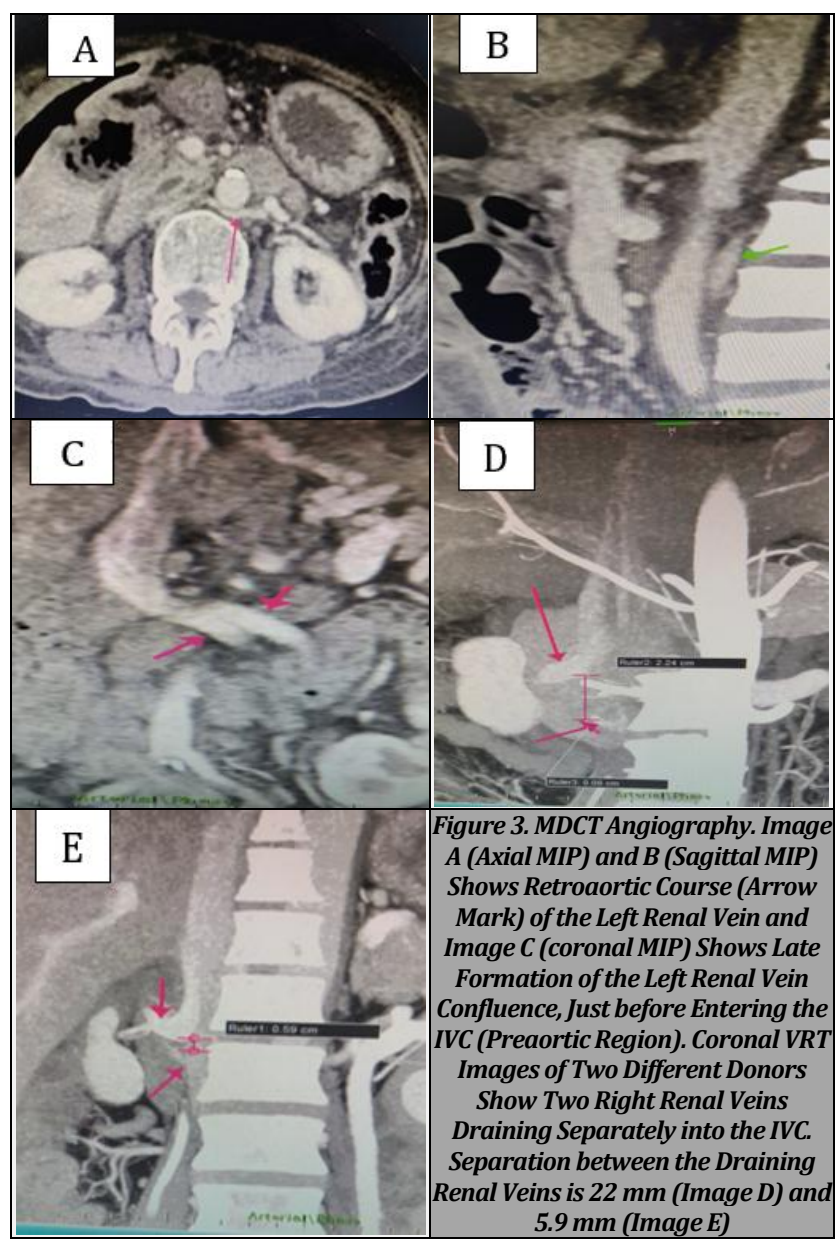

On the left side, both renal veins were having retroaortic course in one donor and circumaortic renal vein in three donors with separate drainage into IVC (Figure $3 \mathrm{~A}$ axial view and $B$ sagittal view). In one candidate late confluence formation took place, at pre-aortic region (Figure 3C). In one candidate, there was extrinsic compression over the pre-aortic left renal vein by SMA (superior mesenteric artery). Four right kidneys drained via double renal vein, among them three were having separate drainage into the IVC (Figure 3 D \& E) and one formed the confluence just before draining into the IVC.
Interobserver agreement was excellent. Both radiologists found nearly the same results except one. A capsular artery was missed by one radiologist but picked up by another. Finally both the radiologists agreed on the presence of capsular artery after reviewing the source images together.

\section{DISCUSSION}

Fifty-five living renal donors i.e. 110 kidneys were evaluated by MDCT angiography. Forty-three (78.18\%) donors were females and twelve were males (21.82\%). Age range was from 24 to 65 years. Mean age was $45.2+-10.5$ years. The most common age group that volunteered for the renal donation was 41 - 50 years of age (18 / 55 i.e. $32.73 \%$ ) followed by 51 60 years of age (15 / 55 i.e. $27.27 \%$ ). All donors were females in the age group of $21-40$ years. Females were the most common in all age groups except in the age range of $61-70$ years. In most number of donors (77 / 110 i.e. $70 \%$ ) in our study, each kidney was supplied by single renal artery, arising from the abdominal aorta. This finding correlated with that of other investigators like C. Llado et al. ${ }^{9}$ in 2017 and Mehta G et al. ${ }^{10}$ in 2014. Diameter of the accessory artery ranged from 0.3 mm - 4 mm in our study. Satyapal et al. ${ }^{7}$ described the diameter range for an accessory renal artery between 0.2 and $3 \mathrm{~mm}$.

$30 \%$ of the donors were having accessory or polar renal arteries (5.45\%, 6 out of 110 kidneys) or capsular arteries ( $2.72 \%, 3$ out of 110 arteries). $50 \%$ of the polar arteries arose directly from the abdominal aorta and $50 \%$ of them from the main renal artery. A capsular artery was so thin and attenuated that it was missed by one radiologist but picked up by another. Two renal arteries were detected in $26.36 \%$ and three renal arteries were detected in $3.64 \%$ of donors. ${ }^{11}$ In two donors, caliber of the main renal artery and accessory artery were same. Early branching was recorded in total 6 kidneys among 110 kidneys (5.45 \%). Earlier studies done by Jee Won Chai11 in 2008 and by Holden A et al.12 in 2005 found that prevalence of early branching was in the range of $10-12$ $\% .92 .72 \%$ (102 out of 110 ) of the donors in our study were having single draining renal veins on each side and $7.28 \%$ (8 out of 110 kidneys) were having double renal veins. The prevalence of the supernumerary vein has been reported to be in the range of $9-28 \%{ }^{12,13}$ In three donors double right renal veins were having separate opening into IVC and in one donor both the right renal veins fused just before drainage into IVC.

On the left side, three donors $(5.45 \%, 3$ out of 55 left kidneys) were having circumaortic renal vein and one donor (1.82 \%, 1 out of 55 left kidneys) was having retroaortic renal vein. These left sided double renal veins drained separately into the IVC. 3 - $17 \%$ of donors were having circumaortic renal vein 14,15 and $3 \%$ of them having retroaortic vein, as reported in literature. ${ }^{14,16}$ In one donor (1.82 \%, 1 out of 55 left kidneys) late confluence formation took place, at pre-aortic region. Jee Won Chai et al. ${ }^{11}$ and Kim JK et al. ${ }^{17}$ reported that this variation was detected in $10.8 \%$ and $16 \%$ of donors respectively. Low prevalence in our study could be due to either lesser prevalence in Indian population than any other population or due to inclusion of lesser number of individuals in the study. 


\section{CONCLUSIONS}

In the past few years, renal transplantation has become the treatment of choice for the end stage renal disease. Triple phase MDCT combined with 3D-CT angiography is the imaging modality of choice for the presurgical work up of the living renal donors for nephrectomy. It provides minimally invasive, highly accurate and detailed renal parenchymal and vascular anatomic evaluation and hence helps the surgeon in planning regarding the proper donor selection, kidney to be harvested, best surgical approach for renal harvesting (fasten the procedure of graft harvesting) and to minimize post-operative complications (risk of vascular injury) for both the donor as well as the recipient. It will detect the anatomical variation of the kidney and various vascular anomalies in the renal donors and hence can modify the plan of action of the transplant surgeons.

\section{Limitations}

Operative evaluation of the renal vessel is considered as gold standard. However, non-availability of the data on the surgical correlation of the renal vascular anatomy and its variations imposed the biggest drawback. This lacuna might have caused some bias that probably led to false positive or false negative results. Another drawback could be the lesser number of study population.

\section{Recommendations}

Accuracy of the MDCT angiography should be correlated with surgical findings (considered as gold standard). So further study including surgical correlation along with larger study population is recommended.

Data sharing statement provided by the authors is available with the full text of this article at jemds.com.

Financial or other competing interests: None.

Disclosure forms provided by the authors are available with the full text of this article at jemds.com.

We are thankful to Dr. Shishir, Associate professor, Department of Community Medicine, IGIMS, Patna for all the help in data analysis. Author contributions - Manisha Kumari contributed to concept, designing of study, data analysis, manuscript preparation. Govind Kumar contributed to data analysis, literature search and manuscript review. S K Suman contributed in critical review of the manuscript. Manmit Patel contributed in data compilation. All authors finally approved this study.

\section{REFERENCES}

[1] Sasaki TM, Finelli F, Bugarian E, et al. Is laparoscopic donor nephrectomy the new criterion standard? Arch Surg 2000;135(8):953-47.
[2] Sebastia C, Peri L, Salvador R, et al. Mutidetector CT of living renal donors: lessons learned from surgeons. Radiographics 2010;30(7):1875-90.

[3] Platt JF, Ellis JH, Korobkin M, et al. Helical CT evaluation of potential kidney donors: findings in 154 subjects. AJR Am J Roentgenol 1997;169(5):1325-30.

[4] Kim JK, Kim JH, Base SJ, et al. CT Angiography for evaluation of living renal donors: comparison of four reconstruction methods. AJR Am J Roentgenol 2004;183(2):471-7.

[5] Kawamoto S, Montgomery RA, Lawler LP, et al. Multidetector CT angiography for preoperative evaluation of living laparoscopic kidney donors. AJR Am J Roentgenol 2003;180(6):1633-8.

[6] Kumar A, Das SK, Srivastava A. Expanding the living related donor pool in renal transplant: use of marginal donors. Transplant Proc 2003;35(1):28-9.

[7] Satyapal KS, Haffejee AA, Singh B, et al. Additional renal arteries: incidence and morphometry. Surg Radiol Anat 2001;23(1):33-8.

[8] Kawamoto S, Fishman EK. MDCT angiography of living laparoscopic renal donors. Abdom Imaging 2006:31(3):361-73.

[9] Llado C, Fuentes S, Mariano J, et al. Computed tomography renal angiography in living donors and its correlation with surgery. Rev Argent Radiol 2017;81(4):262-9.

[10] Mehta G, Arole V. Accessory renal arteries: a cadaveric study. International Journal of Biomedical and Advance Research 2014;5(4):204-6.

[11] Chai JW, Whal Lee, Yin YH, et al. CT angiography for living kidney donors: accuracy, causes of misinterpretation and prevalence of variation. Korean J Radiol 2008:9(4):333-9.

[12] Holden A, Smith A, Dukes P, et al. Assessment of 100 live potential renal donors for laparoscopic nephrectomy with multi-detector row helical CT. Radiology 2005:237(3):973-80.

[13] Rydberg J, Kopecky KK, Tann M, et al. Evaluation of prospective living donors for laparoscopic nephrectomy with multisection CT: the marriage of minimally invasive imaging with minimally invasive surgery. Radiographics 2001;21Spec No:S223-36.

[14] Kawamoto S, Montgomery RA, Lawler LP, et al. Multidetector row $\mathrm{CT}$ evaluation of lining renal donors prior to laparoscopic nephrectomy. Radiographics 2004;24(2):453-66.

[15] Urban BA, Ratner LE, Fishman EK. Three-dimensional volume-rendered CT angiography of the renal arteries and veins: normal anatomy, variants and clinical applications. Radiographics 2001;21(2):373-86.

[16] Smith PA, Ratner LE, Lynch FC, et al. Role of CT angiography in the preoperative evaluation for laparoscopic nephrectomy. Radiographics 1998;18(3):589-601.

[17] Kim JK, Park SY, Kim HJ, et al. Living donor kidneys: usefulness of multidetector row CT for comprehensive evaluation. Radiology 2003;229(9):869-76. 